\title{
Neuroendocrine Tumor Arising from Common Bile Duct: A Case Report and Literature Review
}

\author{
Sungjun Hwang, Jung Wook Seo* \\ Department of Radiology, Ilsan Paik Hospital, Inje University, College of Medicine, Goyang-Si, Korea \\ Email: *seojwrad@paik.ac.kr
}

How to cite this paper: Hwang, S. and Seo, J.W. (2017) Neuroendocrine Tumor Arising from Common Bile Duct: A Case Report and Literature Review. Advances in Computed Tomography, 6, 28-33. https://doi.org/10.4236/act.2017.64005

Received: October 21, 2017

Accepted: November 21, 2017

Published: November 24, 2017

Copyright $\odot 2017$ by authors and Scientific Research Publishing Inc. This work is licensed under the Creative Commons Attribution International License (CC BY 4.0).

http://creativecommons.org/licenses/by/4.0/

\begin{abstract}
Neuroendocrine tumor (NET) arising from common bile duct (CBD) is a rare disease entity, whose origin is currently in discussion with various theories. We present a case of well-defined solid, exophytic and arterial hypervascular mass arising from CBD with relatively mild dilated central intrahepatic bile ducts in 50-year-old man, which was surgically confirmed to be extrahepatic biliary NET, and reviewed radiologic features of extrahepatic biliary NET in previous literature.
\end{abstract}

\section{Keywords}

Neuroendocrine Tumor, Extrahepatic Bile Duct, Computed Tomography, Magnetic Resonance Imaging, Magnetic Resonance Cholangiopancreatography

\section{Introduction}

Neuroendocrine tumors (NET) originate in the embryonic neural crest cells, which are called Kulchitsky cells [1] [2]. These tumors involve different organs and sites with a majority of the tumors occurring in pancreas, stomach, small bowel, rectum, and appendix [3]; however, primary NETs of the extrahepatic bile ducts have rare incidence, representing only $0.2 \%-2 \%$ of gastrointestinal NETs [2] [4]. The radiologic findings of biliary NET show well-defined hypervascular solid mass that needs to differentiate biliary cancer and other hypervascular tumors. We report a case of NET arising from common bile duct (CBD) with computed tomography (CT), magnetic resonance imaging (MRI) and magnetic resonance cholangiopancreatography (MRCP) findings.

\section{Case Presentation}

A 50-year-old man presented out institution with abnormal liver function test 
results during the health checkup. The initial laboratory studies detected abnormally elevated serum levels of direct bilirubin $(0.49 \mathrm{mg} / \mathrm{dL}$, normal $0-0.30$ $\mathrm{mg} / \mathrm{dL})$, aspartate aminotransferase $(84 \mathrm{U} / \mathrm{L}$, normal $\leq 40 \mathrm{U} / \mathrm{L})$ and alanine aminotransferase $(237 \mathrm{U} / \mathrm{L}$, normal $\leq 41 \mathrm{U} / \mathrm{L})$, alkaline phosphatase $(202 \mathrm{U} / \mathrm{L}$, normal 40 - $130 \mathrm{U} / \mathrm{L}$ ) and gamma-glutamyl transferase (3693 U/L, normal 10 $71 \mathrm{U} / \mathrm{L}$ ). Tumor markers such as cancer antigen 19 - 9 and carcinoembryonic antigen were within the normal range. A contrast-media enhanced abdominal CT (Figure 1(a), Figure 1(b)) demonstrated a $3.6 \times 4.3 \mathrm{~cm}$ sized well-defined mass in the proximal CBD with arterial enhancement of 96 Hounsfield unit (HU), which had relatively low attenuation on delayed phase of $78 \mathrm{HU}$. The mass contained focal low attenuation of cystic portion. Both upstream central intrahepatic bile duct was slightly dilated compared to the size of the mass. There was no evidence of hepatic metastasis, and no significantly enlarged lymph nodes around porta hepatis and paraaortic space. Abdominal MRI revealed well defined, arterial heterogeneous enhancing solid mass on fat-saturated T1-weighted turbofield-echo sequence $\left(\mathrm{TR}=3.6 \mathrm{msec}\right.$; $\mathrm{TE}=1.6 \mathrm{msec}$; flip angle $=12^{\circ}$ ) (Figure $1(\mathrm{c})$ ), which contained focal cystic portions of high signal intensity on breathhold multi-shot T2-weighted sequence $(\mathrm{TR}=1600.0 \mathrm{msec}$; $\mathrm{TE}=112.0 \mathrm{msec}$; flip angle $=150^{\circ}$ ) (Figure $1(\mathrm{~d})$ ). The mass showed diffusion restriction on diffusion weighted imaging $\left(b=800 \mathrm{~s} / \mathrm{mm}^{2}\right.$ ) (Figure $1(\mathrm{e})$ ). Thick-slab $(4 \mathrm{~cm})$ MRCP showed an exophytic extraluminal mass compressing the proximal CBD, resulting in relatively mild dilatation of upstream bile duct and smooth beaking appearance of CHD (Figure 1(f)). Six days subsequent to MRI and MRCP, CBD segmental resection with cholecystectomy and choledochojejunostomy were performed. The patient didn't receive any other management after surgery because he didn't have neuroendocrine symptom or distant metastasis. Gross examination revealed a $4.7 \times 4.3 \times 3.5 \mathrm{~cm}$ sized well-defined mass arising from CBD. Histopathology showed the exophytic mass originating from the submucosal layer without mucosal invasion (Figure $1(\mathrm{~g})$ ). No pathologic lymph node was found. Histological examination (Figure $1(\mathrm{~g})$ ) showed the positive expression for chromogranin (Figure 1(h)) and CD56 on immunohistochemistry which suggests the tumor has neuroendocrine component. The Ki67 labelling index, a proliferative marker, was $3 \%$. The final diagnosis was NET of World Health Organization (WHO) Grade 1. The 4-month follow-up of laboratory and CT study showed no abnormal findings.

\section{Discussion}

Extrahepatic biliary NETs have extremely rare incidence and represent $0.2 \%-2 \%$ of all gastrointestinal NETs [2] [4]. Extrahepatic biliary NETs are most frequently found in the common hepatic duct and the distal common bile duct (19.2\%) followed by the middle of the common bile duct (17.9\%), the cystic duct (16.7\%) and the proximal common bile duct (11.5\%) [4]. The mean tumor diameter was $2.15 \pm 1.2 \mathrm{~cm}$ (ranging from 0.2 to $5.5 \mathrm{~cm}$ ). $34.6 \%$ of extrahepatic bi- 


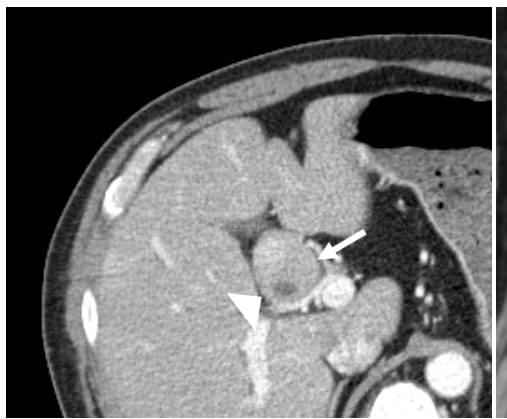

(a)

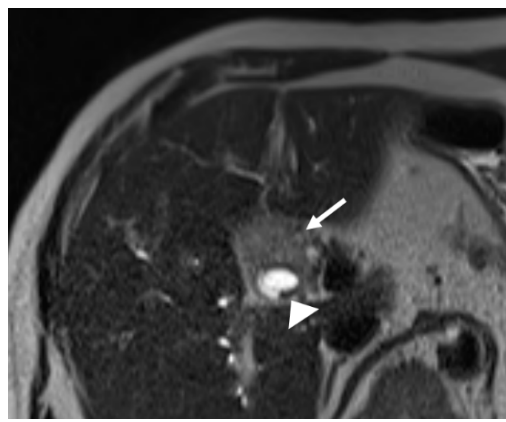

(d)

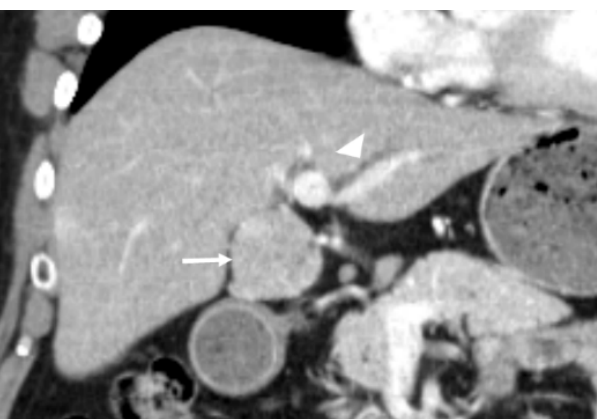

(b)

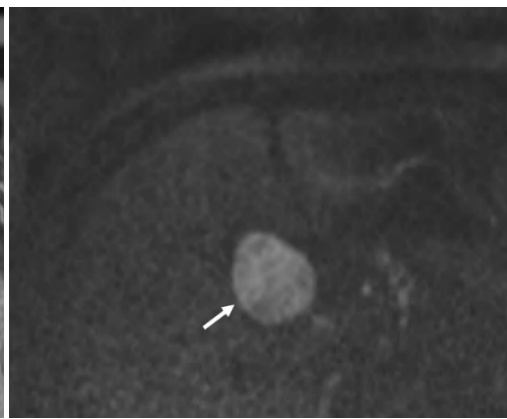

(e)

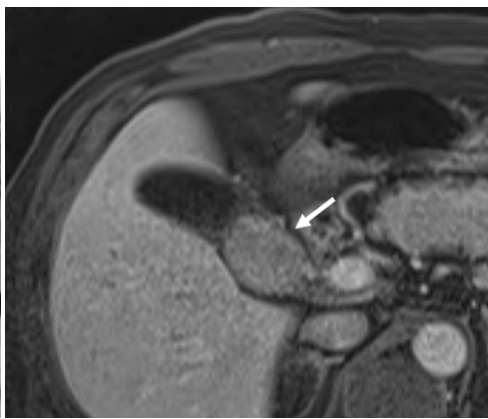

(c)

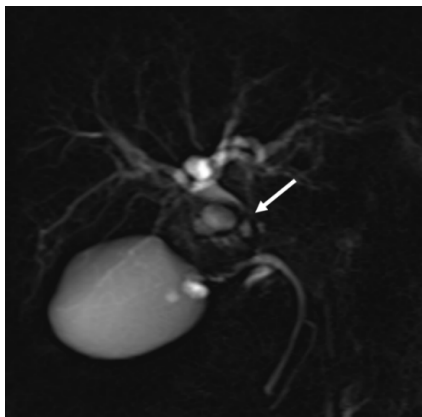

(f)

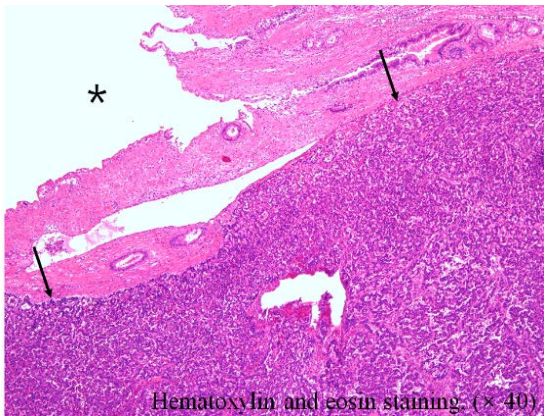

(g)

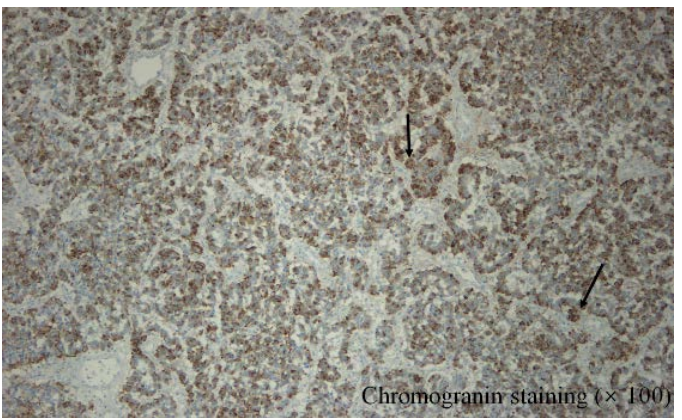

(h)

Figure 1. A 50-year-old man with an incidental finding of an extrahepatic extraluminal biliary tumor: (a) Contrast enhanced abdominal axial CT scan shows a well-defined $3.6 \times 4.3 \mathrm{~cm}$ sized hypervascular mass (arrow) with internal cystic portion (arrowhead); (b) Coronal reconstruction image during the arterial phase shows well-defined extrahepatic mass (arrow) with very slight dilatation of intrahepatic bile duct (arrowhead) comparing to the mass size; (c) Abdominal MRI reveals arterial hypervascular mass (arrow) with mainly solid portion of low signal intensity compared to liver parenchyma on fat-saturated T1-weighted turbo-field-echo sequence $\left(\mathrm{TR}=3.6 \mathrm{msec}\right.$; $\mathrm{TE}=1.6 \mathrm{msec}$; flip angle $\left.=12^{\circ}\right)$; $(\mathrm{d})$ The mass has high signal intensity compared to liver parenchyma (arrow), which contains internal cystic portion (arrowhead) on breath-hold multi-shot T2-weighted sequence (TR = $1600.0 \mathrm{msec}$; $\mathrm{TE}=112.0 \mathrm{msec}$; flip angle $=150^{\circ}$ ); (e) The mass shows diffusion restriction (white arrow) on diffusion weighted imaging $\left(\mathrm{b}=800 \mathrm{~s} / \mathrm{mm}^{2}\right)$; (f) Thick-slab $(4 \mathrm{~cm})$ MRCP shows an exophytic extraluminal mass compressing the proximal CBD (arrow), resulting in mild dilatation of upstream bile duct; (g) Histopathology shows exophytic mass originating from submucosa (arrows) of CBD (asterisk) with rosette appearance and no mucosal invasion (Hematoxylin-Eosin staining, $\times 40$ ); (h) Strong expression of chromogranin (arrows) is noted in the cytoplasm of NET (Immunohistochemical staining, $\times 100$ ).

liary NETs were found to be metastasizing into local lymph nodes (19.23\%) or the liver (16.7\%) [4].

The origin of extrahepatic biliary NET is not clearly discovered yet. Some authors are assuming that biliary NET derive from preexisting neuroendocrine cells which were dispersed throughout the biliary mucosa [5]. Another hypothe- 
sis suggests that the ectopic pancreatic tissue distributed during embryogenesis is the origin of biliary NET [6] [7]. The last theory is about the multipotent stem cell of the biliary mucosa, which are capable of differentiating into NETs and carcinomas [8]. This suggestion well explains the mixed phenotypes of extrahepatic biliary NETs in previous reports, ranging from pure extrahepatic biliary NETs and to carcinomas with scattered neuroendocrine cells [9].

The imaging feature assessment of extrahepatic biliary NET has been limited due to absence of specific description in the previous literature. According to previous radiology case reports, $90.0 \%(9 / 10)$ of these NETs had a well-defined margin with prominence in arterial phase [10]. The mean diameter of these tumors was $2.66 \mathrm{~cm}(1.5-4.5 \mathrm{~cm})$ [10]-[15]. Extrahepatic biliary NETs occasionally metastasize to the liver, gallbladder, pancreas, and in the regional lymph nodes [11] [16]. Referring to the histopathological subtypes in the WHO 2010 classification, these NETs had a wide spectrum of recurrence rate and overall survival [16]. According to the study by Kim et al. [16], extrahepatic biliary NETs metastasized to hepatic parenchyma in 2/7 cases of pure neuroendocrine carcinoma and in 2/7 cases of mixed endocrine-exocrine carcinoma. In contrast, hepatic metastasis was not reported (0/6) for NET grade 1 and grade 2 tumors. Our case of low grade NET without metastasis consists with the result of previous study.

The most common bile duct tumor is cholangiocarcinoma of approximately $80 \%$ [10]. Periductal infiltrating type, the most common type of extrahepatic cholangiocarcinoma manifests as irregular segmental wall thickening lesion which accompanies bile ductal shouldering and marked upstream biliary dilatation. It shows progressive enhancement due to severe desmoplastic reaction [17]. However, in this study, the well-defined exophytic mass shows prominence in arterial phase with very slight intrahepatic bile duct dilatation comparing to the mass size, which is different radiologic findings from cholangiocarcinoma. If that is the case, the differential diagnosis for hypervascular enhancing mass in extrahepatic bile duct or porta hepatis include NET, peripheral nerve sheath tumor, or Castleman's disease. Peripheral nerve sheath tumor commonly manifests as progressive heterogeneous delayed enhancing mass with smooth or lobulating contour [18], of which its incidence is also rare so that only 17 cases of schwannoma of the extrahepatic biliary tract have been reported [19]. These tumors can include calcification, cystic change, bleeding and hyalinization as it grows in size. Castleman's disease of hyaline vascular type occurs as a homogeneously enhancing hypervascular mass which often accompanies calcification.

\section{Conclusion}

In conclusion, the characteristic imaging finding of extrahepatic biliary NET is well-defined, exophytic, arterial hypervascular solid mass without calcifications. It can be helpful to differentiate from other hypervascular tumors. If hepatic or lymph node metastasis exists in initial study, high grade NET should be in con- 
sideration. Although its low incidence to occur in the extrahepatic biliary region, extrahepatic biliary NET should be kept in mind as a possibility in this situation. We report a rare case of extrahepatic biliary NET arising from CBD which has characteristic radiologic findings.

\section{Financial Disclosure}

No funding support or grant was received for this study.

\section{References}

[1] Tomulescu, V., Stanciulea, O., Dima, S., Herlea, V., Stoica Mustafa, E., Dumitrascu, T., Pechianu, C. and Popescu, I. (2011) Diagnosis and Surgical Management in Gastrointestinal Neuroendocrine Tumors. Chirurgia (Bucur), 106, 151-161.

[2] Bhandarwar, A.H., Shaikh, T.A., Borisa, A.D., Palep, J.H., Patil, A.S. and Manke, A.A. (2012) Primary Neuroendocrine Tumor of the Left Hepatic Duct: A Case Report with Review of the Literature. Case Reports in Surgery, 2012, Article ID: 786432. https://doi.org/10.1155/2012/786432

[3] Chang, S., Choi, D., Lee, S.J., Lee, W.J., Park, M.H., Kim, S.W., Lee, D.K. and Jang, K.T. (2007) Neuroendocrine Neoplasms of the Gastrointestinal Tract: Classification, Pathologic Basis, and Imaging Features. Radiographics, 27, 1667-1679. https://doi.org/10.1148/rg.276075001

[4] Michalopoulos, N., Papavramidis, T.S., Karayannopoulou, G., Pliakos, I., Papavramidis, S.T. and Kanellos, I. (2014) Neuroendocrine Tumors of Extrahepatic Biliary tract. Pathology \& Oncology Research, 20, 765-775.

https://doi.org/10.1007/s12253-014-9808-4

[5] Gusani, N.J., Marsh, J.W., Nalesnik, M.A., Tublin, M.E. and Gamblin, T.C. (2008) Carcinoid of the Extra-Hepatic Bile Duct: A Case Report with Long-Term Follow-Up and Review of Literature. The American Surgeon, 74, 87-90.

[6] Price, T.N., Thompson, G.B., Lewis, J.T., Lloyd, R.V. and Young, W.F. (2009) Zollinger-Ellison Syndrome Due to Primary Gastrinoma of the Extrahepatic Biliary Tree: Three Case Reports and Review of Literature. Endocrine Practice, 15, 737-749. https://doi.org/10.4158/EP09022.RAR

[7] Noronha, Y.S. and Raza, A.S. (2010) Well-Differentiated Neuroendocrine (Carcinoid) Tumors of the Extrahepatic Biliary Ducts. Archives of Pathology \& Laboratory Medicine, 134, 1075-1079.

[8] Todoroki, T., Sano, T., Yamada, S., Hirahara, N., Toda, N., Tsukada, K., Motojima, R. and Motojima, T. (2007) Clear Cell Carcinoid Tumor of the Distal Common Bile Duct. World Journal of Surgical Oncology, 5, 6. https://doi.org/10.1186/1477-7819-5-6

[9] Aronsky, D., Z’Graggen, K., Stauffer, E., Lange, J. and Klaiber, C. (1999) Primary Neuroendocrine Tumors of the Cystic Duct. Digestion, 60, 493-496. https://doi.org/10.1159/000007696

[10] Squillaci, S., Marchione, R., Piccolomini, M., Colombo, F., Bucci, F., Bruno, M. and Bisceglia, M. (2010) Well-Differentiated Neuroendocrine Carcinoma (Malignant Carcinoid) of the Extrahepatic Biliary Tract: Report of Two Cases and Literature Review. Journal of Pathology, Microbilogy and Immunology, 118, 543-556. https://doi.org/10.1111/j.1600-0463.2010.02633.x

[11] Lee, J.H., Lee, K.G., Oh, Y.H., Paik, S.S., Park, H.K. and Lee, K.S. (2011) Carcinoid 
Tumors of the Extrahepatic Biliary Tract: Report of Four Cases. Surgery Today, 41, 430-435. https://doi.org/10.1007/s00595-010-4256-6

[12] Pawlik, T.M., Shah, S. and Eckhauser, F.E. (2003) Carcinoid Tumor of the Biliary Tract: Treating a Rare Cause of Bile Duct Obstruction. The American Surgeon, 69, 98-101.

[13] Tsalis, K., Vrakas, G., Geroukis, T., Cheva, A., Roidos, G.N. and Lazarides, C. (2010) Primary Neuroendocrine Tumor of the Extrahepatic Biliary Tree Mimicking Klatskin Tumor. Journal of Gastrointestinal and Liver Diseases, 19, 341-342.

[14] Costin, A.I., Paun, I., Paun, M., Constantin, V.D. and Varcus, F. (2017) Primary Neuroendocrine Tumors-An Extremely Rare Cause of Obstruction of Extrahepatic Bile Ducts: A Case Report. Romanian Journal of Morphology and Embryology, 58, 641-644.

[15] Raspanti, C., Falco, N., Silvestri, V., Rotolo, G., Bonventre, S. and Gulotta, G. (2016) Neuroendocrine Tumor of the Common Bile Duct: Case Report. Il Giornale di Chirurgia, 37, 275-280. https://doi.org/10.11138/gchir/2016.37.6.275

[16] Kim, J., Lee, W.J., Lee, S.H., Lee, K.B., Ryu, J.K., Kim, Y.T., Kim, S.W., Yoon, Y.B., Hwang, J.H., Han, H.S., Woo, S.M. and Park, S.J. (2011) Clinical Features of $20 \mathrm{~Pa}$ tients with Curatively Resected Biliary Neuroendocrine Tumours. Digestive and Liver Disease, 43, 965-970. https://doi.org/10.1016/j.dld.2011.07.010

[17] Han, J.K., Choi, B.I., Kim, A.Y., An, S.K., Lee, J.W., Kim, T.K. and Kim, S.W. (2002) Cholangiocarcinoma: Pictorial Essay of CT and Cholangiographic Findings. Radiographics, 22, 173-187. https://doi.org/10.1148/radiographics.22.1.g02ja15173

[18] Rha, S.E., Byun, J.Y., Jung, S.E., Chun, H.J., Lee, H.G. and Lee, J.M. (2003) Neurogenic Tumors in the Abdomen: Tumor Types and Imaging Characteristics. Radiographics, 23, 29-43. https://doi.org/10.1148/rg.231025050

[19] Marin Campos, C., Garcia Sanz, I., Munoz de Nova, J.L., Valdes de Anca, A. and Martin Perez, M.E. (2016) Schwannoma of the Biliary Tract Resembling Cholangiocarcinoma: A Case Report and Review. Annals of the Royal College of Surgeons of England, 98, e143-e146. https://doi.org/10.1308/rcsann.2016.0189 